\title{
As famílias e a luta pelo direito de aprender dos estudantes da educação especial na escola comum
}

Douglas Christian Ferrari de Melo

Andressa Caetano Mafezoni

Universidade Federal do Espírito Santo (Brasil)

\section{Resumo}

texto tem como objetivo discutir a atuação das famílias em busca do direito de aprender dos estudantes da educação especial na escola comum por meio de um estudo de natureza qualitativa. Para essa discussão, nos fundamentamos na Teoria Crítica dos Direitos Humanos construída por Flores (1985, 2008, 2010, 201 1). Para a produção de dados, realizamos a técnica do grupo focal em um fórum composto por pais de estudantes matriculados em diferentes escolas de um município da Região Metropolitana da Grande Vitória / ES. A análise indica que a efetivação do direito de aprender passa pela interligação com outros direitos, ao passo que o processo de luta das famílias avança na garantia ao direito à educação dos filhos quando deixam de ser invisíveis para a escola.

Palavras-chave: : Direito de aprender. Famílias. Educação especial. Educação inclusiva.

\section{Families and the struggle for special education students' right to learn in regular school}

\section{Abstract}

The text aims to discuss the role of families in the search for the right to learn of special education students in regular schools through a qualitative study. For this discussion, we based ourselves on the Critical Theory of Human Rights constructed by Flores (1985, 2008, 2010, 201 1). For data production, we carried out the focus group technique in a forum composed of parents of students enrolled in different municipals schools in a municipality in the Metropolitan Region of Vitória / ES. The analysis indicates that the effectiveness of the right to learn goes through the interconnection with other rights, while the process of struggle of families advances in guaranteeing the right to education of their children when they are no longer invisible to the school.

Keywords: Right to learn. Families. Special education. Inclusive education.

\section{Las familias y la lucha por el derecho de aprender de los estudiantes de la educación especial en la escuela común}

\section{Resumen}

El texto tiene como objetivo discutir la actuación de las familias en la búsqueda del derecho a aprender de los estudiantes de la educación especial en la escuela común a través de un estudio cualitativo. Para esta discusión, nos basamos en la Teoría Crítica de los Derechos Humanos, 
As famílias e a luta pelo direito de aprender dos estudantes da educação especial na escola comum

construida por Flores (1985, 2008, 2010, 201 1). Para la obtención de los datos, realizamos la técnica de grupo focal en un foro compuesto por padres de alumnos matriculados en diferentes escuelas de un municipio de la Región Metropolitana de la Grande Vitória/ES. El análisis indica que la efectividad del derecho a aprender necesita de la interconexión con otros derechos, mientras que avanza el proceso de lucha de las familias para garantizar el derecho a la educación de los hijos cuando dejan de ser invisibles para la escuela.

Palabras clave: Derecho a aprender. Familias. Educación especial. Educación inclusiva.

\section{Introdução}

O texto da Constituição Federal de 1988 trouxe a possibilidade de ampliação, discussão e efetivação dos direitos no campo educacional e determinou que a educação fosse considerada um direito humano de todos os cidadãos brasileiros. De acordo com Cury (2008), no contexto de ruptura da ordem legal existente, a Constituição Federal possibilitou novos contornos organizacionais, implicando que todos tivessem acesso à cidadania. Dessa maneira, para que a cidadania se configurasse como direito de todos, era fundamental que houvesse algo comum ou universal. A partir dessa centelha, expressa e garantida no texto constitucional, é que a educação escolar passou

2 a ser proclamada como direito.

Nesse ínterim, a legislação educacional brasileira tornou-se significativa e incisiva quanto ao direito de todos os estudantes em ter acesso à educação, incluídas a permanência e aprendizagem conforme disposto no texto constitucional de 1988 que considera, no Artigo 205:

A educação, direito de todos e dever do estado e da família, será promovida e incentivada com a colaboração da sociedade, visando ao pleno desenvolvimento da pessoa, seu preparo para o exercício da cidadania e sua qualificação para o trabalho (BRASIL, 1988).

Podemos depreender quatro pilares do artigo constitucional. $\bigcirc$ primeiro é a educação como um direito de todas as pessoas; o segundo, é a educação como um dever do Estado; o terceiro é a educação como dever da família; e o quarto, a educação proporcionada e estimulada pela sociedade. Esses quatro pilares sustentam a ideia de uma sociedade mais justa e igualitária com base na educação como direito de todos, ou seja, uma educação 
inclusiva para os grupos historicamente excluídos, e, especificamente, nesta discussão, para os estudantes da educação especial na escola comum.

Nessa perspectiva, tomamos por base o direito de todos à educação, entendendo que todos têm o direito de estar, permanecer na escola e aprender, independentemente de suas especificidades, conforme Melo e Mafezoni (2019), e que a família ocupa um lugar de destaque na luta pelo direito de aprender no processo de escolarização de seus filhos, o que se configura como uma via de colaboração com a escola.

Diante do enunciado, a discussão que se coloca é sobre o direito de aprender dos estudantes da educação especial na escola comum, no que concerne o direito à educação, cogitando que o direito de aprender está contido no direito à educação com a premissa da educabilidade de todos. Dessa maneira, concebemos que o acesso ao conhecimento sistematizado e historicamente construído deve ser oportunizado, ao passo que esses estudantes, assim como os outros, precisam aprender português, matemática, história, geografia, ciências, artes etc.

Essa possibilidade também se constrói por meio do olhar para o humano, para o outro, para o diferente de mim. Assim, aspiramos que a mediação desenvolvida pelo educador seja potencializada pela compensação social concretizada na aprendizagem, favorecendo o desenvolvimento das funções psicológicas superiores do aluno com deficiência, como afirma Hell (2020).

Assim, a seguinte problematização se torna obrigatória: os alunos público-alvo da educação especial estão aprendendo? (MELO; MAFEZONI, 2019). Temos nos debruçado sobre essa problematização por meio de uma pesquisa maior em estudos, debates e na escrita de textos acadêmicos sobre o tema. Nessa perspectiva, temos discutido por meio das teorias críticas os vetores das políticas públicas e das práticas pedagógicas. Temos problematizado a necessidade do início de uma nova fase na educação especial brasileira que se traduza no direito de aprender em sala de aula, o que exige um novo fazer pedagógico com estes alunos que têm potencialidades e podem se beneficiar do processo de escolarização.

Para o texto ora em tela, apoiados na argumentação anterior, realizada por Melo e Mafezoni (2019), adicionamos à discussão uma nova pergunta: qual tem sido a atuação das famílias na luta pela garantia do direito 
de aprender dos estudantes da educação especial na escola comum? Para este momento da pesquisa, lançamos mão da técnica do grupo focal em um fórum de pais de alunos matriculados em diferentes escolas de um município da Região Metropolitana da Grande Vitória, no Estado do Espírito Santo, com o objetivo de elucidar sua atuação no processo de escolarização dos filhos.

Nessa direção, após a introdução, dividimos este texto em três momentos para dialogarmos com o leitor. No primeiro, apresentamos a técnica do grupo focal, no segundo, discutimos a luta pelo direito de aprender com a luta pela dignidade humana e, no terceiro, discutimos os dados produzidos, destacando a atuação das famílias.

Nesse ínterim, é preciso afirmar a centralidade e o protagonismo das políticas públicas como um imperativo ético e político para efetivação do direito de aprender, que defendemos em concordância com Freitas (2014). Entendemos que esse direito depende de outros não disponíveis no ato da aprendizagem de grande parte dos alunos, não apenas os com deficiência, como também o direito à habitação, à alimentação, à cultura, à saúde. Segundo o autor, a tese liberal da oferta da educação por mérito transfere para o sujeito a culpa por não ter acessado os outros direitos e, ao fim, pelo insucesso de sua aprendizagem. A sonegação da aprendizagem nos remete à "[...] amplitude das aprendizagens incluídas e que serão consideradas "direitos $[\ldots]^{\prime \prime}$, como afirma Freitas (2014, p. 1107 ).

Reafirmamos que o direito à educação não se reduz ao acesso, mas também é necessária a garantia de permanência e a qualidade que proporcione aos alunos a efetivação da aprendizagem e do desenvolvimento. Nesse alinhamento, o direito à educação também envolve o direito à aprendizagem e o desenvolvimento pleno como pessoa. Dessa maneira, postulamos que o direito à aprendizagem não é uma concessão, mas, sim, uma conquista obtida por meio de lutas empreendidas pela sociedade civil, em busca de igualdade de direitos e de justiça social.

\section{O grupo focal como uma possibilidade de entendimento da atuação das famílias pela luta do direito de aprender dos filhos}

Iniciamos este momento retomando à pergunta que tem nos inquietado, como o fazem Melo e Mafezoni (2019): o discurso oficial é que todos 
devem estar na escola, mas todos estão aprendendo? Ou seja, os estudantes da educação especial na escola comum estão aprendendo? Gomes (2005) argumenta que, embora uma pesquisa não possa dar respostas finais às perguntas que estuda, tem-se dispensado grande esforço para criar processos que aumentem a provável precisão de respostas de pesquisa.

Mesmo que não obtenhamos respostas finais sobre o tema proposto, ainda concordamos com Gomes (2005) que é necessário aperfeiçoar processos que permitam aproximações cada vez mais fidedignas com relação ao fenômeno estudado. Assim, durante a realização da pesquisa maior e de nossas reflexões, surgiu a necessidade de ouvir as famílias dos estudantes, suas impressões e vivências em relação à escolarização dos seus filhos na escola inclusiva.

Nessa perspectiva, por se tratar de uma pesquisa qualitativa, lançamos mão do grupo focal, realizado no segundo semestre do ano de 2018 , composto por representantes de 15 famílias (pais, mães, avós, tios e responsáveis) de estudantes da educação especial, matriculados em escolas da rede de um município da Região da Grande Vitória/ES. Esse momento aconteceu em um fórum de pais, objetivando dar precisão, confiabilidade e validade aos resultados obtidos.

De acordo com uma apresentação realizada em uma das reuniões pelo representante do fórum de pais do município, nasceu a mobilização por um espaço de discussão e proposições no ano de 2017, advinda das dificuldades vivenciadas pelos alunos da educação especial nas escolas da rede municipal, e a necessidade de avanços nos processos de acolhimento. Foram realizadas reuniões integrativas, das quais houve a participação da sociedade civil, representantes da secretaria de educação municipal e do ministério público.

Destacamos que, a partir de nossa solicitação para a realização do grupo focal, foi convocada uma reunião pelo fórum em parceria com a Secretaria Municipal de Educação. Nessa reunião, realizamos uma palestra, na qual foi abordado o direito à aprendizagem. Após o encerramento da apresentação, com o objetivo de ouvir os participantes, lançamos a pergunta disparadora: o que temos vivido enquanto família de alunos da educação especial em relação ao direito de aprender? Dessa maneira, o grupo focal, que durou uma hora e vinte e cinco minutos, permitiu compreendermos as 
questões levantadas com mais profundidade, na medida em que consideramos que o entendimento dos participantes, é a própria unidade de análise.

Dessa maneira, após a transcrição das falas, organizamos em um primeiro momento um ajuste para pensarmos em uma possível produção dos dados. Após uma primeira organização, constatamos que surgiram categorias e subcategorias, mas que se interpenetravam, e que não conseguiríamos apresentá-las e discuti-las em sua totalidade, o que poderia nos levar a um equívoco de posicionamento dos depoimentos.

Por esse motivo, decidimos compor dois eixos que nos ajudaram a organizar e a compreender a discussão realizada pelas famílias sobre os tópicos levantados e discutidos por eles mesmos a partir da pergunta disparadora. primeiro eixo de discussão foi nomeado "Contextualizando o movimento da família e o espaço escolar, e o segundo: $\bigcirc$ que vem a ser o direito de aprender?".

É importante ainda destacar que o grupo focal é uma técnica de investigação que aproxima o pesquisador e os sujeitos da pesquisa, na medida em que pode ouvir os participantes e verificar as informações no lócus da produção de dados.

ambiente proporcionado pela organização do grupo focal permite interação entre os membros do grupo; as informações prestadas por um dos integrantes estimulam os demais a falar sobre o assunto; o debate entre eles enriquece a qualidade das informações (GOMES, 2005, p. 281 ).

Dessa maneira, a possibilidade de discutir um assunto de convergência de um coletivo que vive situações semelhantes em relação às lutas, acolhimento e aprendizagem de seus filhos, entre outros aspectos, proporciona mais confiança para expressar suas ideias e entendimento acerca do tema em nosso entendimento.

\section{A luta pela aprendizagem como fio condutor do direito de aprender}

Para dar continuidade à discussão, apresentamos uma definição de direitos sociais a partir do método relacional da Teoria Crítica dos Direitos 
Humanos, construído por Flores (1985, 2008, 2010, 201 1), que se refere [...] à forma de acesso a bens que estão condicionados pelos contextos sociais (sistema de valores e sistemas de posição com respeito a bens) dos quais e para os quais surgem (SIMÕES, 2013, p. 213).

Flores (2011) rebate as teses que relacionem os direitos com a neutralidade, a abstração, o formalismo, ou seja, quaisquer teses que concebam os direitos desvinculados/autonomizados das práticas sociais com o objetivo de ocultar as relações sociais e os interesses hegemônicos. Portanto, os direitos, com destaque para os sociais, são condicionados social e historicamente por uma ordem de relações sociais, o que indica que são criados e recriados no processo de luta contra as desigualdades sociais e na abertura de espaços para a luta pela dignidade humana por parte dos marginalizados, de acordo com Flores (201 1). A unidade dos direitos humanos está na luta política, como afirma Herrera (2011).

Depreende-se, portanto, que os direitos não são questões abstratas, uma vez que foram, por um lado, alcançados pela via da mobilização das classes populares, e entendidos como conquista nesse sentido, e, por outro, uma ação integradora dessas classes ao Estado, incluídos aí os direitos civis como expressão da classe burguesa, exigindo a ampliação do repertório de direitos. Nessa perspectiva, a Constituição Federal de 1988 ampliou e explicitou os direitos sociais e, consequentemente, aumentou consideravelmente as obrigações do Estado, inclusive na área educacional, nos três níveis de Governo com a noção de sistemas de ensino.

Dessa maneira, corroboramos com Duarte (2007) que o Estado estabelecido por essa Constituição foi o "Estado social", nos termos liberais, com a finalidade de intervir para diminuir as desigualdades sociais, tendo em vista que, nesse tipo de Estado,

[...] é a elaboração e a implementação das políiticas públicas objeto, por excelência, dos direitos sociais - que constitui o grande eixo norteador da atividade estatal, o que pressupõe uma reorganização dos poderes em torno da função planejadora, tendo em vista a coordenação de suas funções para a criação de sistemas públicos de saúde, educação, previdência social etc (DUARTE, 2007, p. 694). 
Levantando essa premissa, entendemos que os direitos sociais, na verdade, ficaram restritos à legitimação das regras formais da democracia, portanto, reduzidos aos direitos políticos, ou seja, ao processo limitado ao voto, e não à soberania popular, assim como a separação entre os aspectos econômicos e sociais. Analisando a década de 1990 e a primeira metade da década de 2000, Lima argumenta que tal fato ocorre porque, numa perspectiva de Estado Capitalista,

[...] a democracia foi sempre uma ameaça ao projeto do capital, mesmo se tratando da democracia burguesa, uma vez que o Estado liberal repousa sobre uma igualdade perante a lei, o que pressupõe uma igualdade formal e ficcional (LIMA, 2008, p. 93).

Nesse sentido, a desigualdade praticada na esfera econômica é uma característica que serve para encobrir a desigualdade real. Além disso, o capital conta com o Estado, representado pela sociedade política e pela sociedade civil, como um aliado no auxílio ao processo de acumulação capitalista ao tentar promover a ocultação da dominação social. Insistimos na palavra "tentar", pelo fato de que muitas vezes há êxito nesse processo, mas nem sempre.

Nessa esteira, as políticas públicas, como ação estatal, são a materialização de um ordenamento jurídico na medida em que toda política pública reflete, em maior ou menor grau, uma política constitucional, o que vai influenciar o papel a ser desenvolvido pelas administrações públicas, bem como os marcos institucionais e políticos nos quais devem operar, de acordo com Ohlweiler (2010).

Por isso, as políticas públicas, como os direitos sociais incluídas nas normas constitucionais, obrigam os Poderes Públicos à observância de tais direitos, pois "[...] transcendem os direitos individuais", como diz Silva (2010, p. 275), e são considerados por Batista (2012, p. 138) "as liberdades públicas".

\section{Contextualizando o movimento da família e o espaço escolar}

É importante atentarmos para o fato de que a escola e a família cumprem papéis diferentes na sociedade, mas ao mesmo tempo têm o objetivo comum que é a educação de crianças em âmbito formal. Faria Filho (2000) 
argumenta que a forma e a intensidade das relações entre escolas e famílias variam enormemente e estão relacionadas a fatores como, estrutura e tradição de escolarização das famílias, classe social, meio urbano ou rural, número de filhos, ocupação dos pais, entre outros. Nessa perspectiva, Faria Filho (2000, p. 14) destaca: "[...] gestores e professores, centrados em uma visão escolarizada do problema, eles não põem em dúvida o lugar construído para e pela escola, em relação às demais instituições sociais, dentre elas a família".

Entendemos que, à medida em que foram construídos lugares e papéis sociais para e pela escola, a escolarização de estudantes da educação especial vem historicamente se desenhando por meio da exclusão educacional. Concordamos com a argumentação de Mafezoni e Pletsch (2019) de que a sistematização dos saberes produzidos em diferentes culturas também solicitou dos indivíduos um papel social que atendesse aos seus interesses sócio-políticos-econômicos e ideológicos, fossem individuais ou coletivos, cobrando de seus usuários o retorno de que deveriam se enquadrar nas teorias formuladas em cada momento histórico.

Recentemente, a universalização da educação oportunizou que o paradigma da inclusão escolar regatasse a diversidade e a diferença, nos apresentando o desafio de construirmos uma educação para todos e para cada um em particular, aliada ao direito à aprendizagem.

Dessa maneira, a mudança do paradigma da exclusão em direção à inclusão escolar tem movimentado as famílias de estudantes da educação especial na escola comum na luta pela garantia do direito de aprender. Esse aspecto se mostra interessante na medida em que a família tem apostado na escola. Nesse sentido, a família argumenta, cobra, dialoga e quer ser ouvida. Além disso, cada família tem focos, objetivos, anseios e expectativas diferentes em relação à vida escolar de seus filhos, e, por isso, nos perguntamos: como elas e sua luta pelo direito de aprender de seus filhos têm se inserido no contexto escolar?

Para argumentar sobre essa pergunta, é importante ter em vista que cada estado e respectivos municípios tem uma vivência em relação à educação especial/inclusiva. Esse ponto contém, para além das políticas e legislação nacional, as políticas e legislações estaduais e municipais, investimentos, infraestrutura, condições de trabalho docente, formação continuada, dentre outros, 
com diferentes contornos, ações e saberes/fazeres. Seria ingênuo pensar que o mesmo processo é linear em todos as regiões e escolas do País.

propósito de análise e discussão para este texto é problematizar e tensionar os dados da pesquisa que podem ter pareamento com outras realidades regionais e nacionais. Como dissemos anteriormente, as famílias dos estudantes que participaram do grupo focal construíram a discussão a partir da pergunta norteadora: o que temos vivido enquanto família de alunos, público da educação especial, em relação ao direito de aprender? A partir daí, as famílias teceram um diálogo com os pesquisadores e demais presentes sobre suas vivências na escola.

Para dar início ao diálogo, apresentamos um primeiro ponto de inquietação que aponta para um descompasso entre os procedimentos relativos à escolarização dos filhos e algumas ações dos profissionais nas quais estão contidas o ensinar, aprender, se relacionar e incluir.

Foram expressas situações em que as ações da escola não estão claras, o que esbarra numa crítica ao trabalho realizado pelo professor da modalidade educação especial, na ação de pedagogos, na relação e interação com a família, e ainda no questionamento sobre a aprendizagem que não pode ser reduzida a atos mecânicos de ler e escrever.

Ela foi privada do atendimento de educação especial da escola e não do $A E E$, mas foi a educação especial da escola e a pedagoga que tirou esse atendimento dela [...] em uma conversa informal ela falou assim: "a B. dá conta da turma, a B. acompanha a turma". Mas o que que é dar conta da turma? É escrever? A minha filha pode muito mais do que isso, mas no momento ela precisa de um auxílio e esse auxilio vem através da educação especial (RESISTÊNCIA, 2018).

Esse excerto aponta para a organização do suporte realizado pela educação especial na escola e demonstra a importância e a necessidade de realização de um trabalho de parceria entre a escola e a família, e ainda o processo de ensino-aprendizagem.

É possível vislumbrar que, para esse familiar, a educação especial ocupa um papel importante no processo educacional, ao passo que pode ser a via do aprendizado, que poderá oportunizar o acesso do estudante aos conteúdos e a aprendizagem. Leva-se em consideração que a estudante sabe ler 
e escrever, mas isoladamente somente essas habilidades vistas não garantem a continuidade do processo de ensino-aprendizagem. Assim, tanto a escola como a família, que são lócus de desenvolvimento e aprendizagem humana, têm um papel fundamental no processo de escolarização dos estudantes.

Nesse sentido, concordamos com Dessen (2007) que é importante compreendermos a relação família-escola, na medida em que permite identificar aspectos ou condições que geram conflitos e ruídos nas comunicações e, consequentemente, nos padrões de colaboração entre eles. Para Polonia e Dessen (2005), quando a família e a escola mantêm boas relações, as condições para um melhor aprendizado e desenvolvimento da criança podem ser maximizadas.

Também encontramos nas falas nos momentos em que os pais/responsáveis se posicionaram acerca de sua exclusão no acompanhamento do processo de ensino-aprendizagem dos filhos.

Em nenhum momento me procurou [...] para me passar porque estaria fazendo isso, e eu tive que ir até lá em uma conversa informal (FORÇA, 2018).

[...]

Eu pedi uma reunião com a diretora da escola enquanto mãe de aluno porque eu não queria pensar mais como colega de trabalho (VIGOR, 2018).

Tanto no primeiro excerto, relacionado ao descompasso entre os procedimentos relativos à escolarização, como no segundo, acerca de sua exclusão do acompanhamento do processo de ensino-aprendizagem dos filhos, observamos uma relação complementar, imbuída da dificuldade no relacionamento entre família e escola. Nesse caso, devemos pensar além do convívio entre as duas instituições, na medida em que as redes de ensino vêm lidando com modificações tanto em nível de políticas/legislação como de estrutura físico-organizacional para atender a solicitação demandada pelo movimento de educação inclusiva escolar.

Podemos argumentar que esses conflitos de relacionamento também estão ligados às concepções de homem e sociedade, deficiência (anormalidade) e inteligência (normalidade). Concebemos que concepções estigmatizantes, baseadas na expectativa da não ou pouca aprendizagem, contribuem para a naturalização de uma cultura escolar que não se empenha 
em contribuir para o desenvolvimento do aluno, conforme Mafezoni e Simon (2020, p. 12) afirmam, "[...] constituindo um mero cumprimento estéril do que dispõe a legislação educacional".

Ao mesmo tempo, também são reportadas falas em relação à corresponsabilidade da família no processo de ensino-aprendizagem, seja em relação ao acompanhamento escolar, seja na administração posológica de medicamentos e a intersetorialidade. De acordo com Oliveira e Araújo (2010), a relação entre família e escola tem se mantido por meio de situações vinculadas a algum tipo de problema, o que pouco contribui para a construção de uma parceria baseada em fatores positivos e gratificantes relacionados ao aprendizado, desenvolvimento e sucesso dos alunos.

Nós, enquanto família, somos responsáveis e temos um papel importante. Eu procuro acompanhar em todas as atividades, e ele não consegue acompanhar na sala. Eu sempre peço para professora mandar para casa (COMBATE, 2018).

$[\ldots]$

melhoramento dele do ano passado, nesse ano parece que tá indo pra trás, justamente por causa da neuropediatra que nós estamos precisando [...]. $\bigcirc$ meu neto não tá mais escrevendo como tava escrevendo [...] tudo que ele aprendeu de bom no ano passado, ele tá um fracasso, e não é falta da família acompanhar [...]. As crianças também precisam do tratamento digno e precisam do remédio para criança ser o que ela tem que ser na vida e na sociedade. Ela tem que ter o acompanhamento completo ISUPERAÇÃO, 20181 .

Sobrinho (2009) aponta que os pais não têm expectativas de que as escolas sejam as únicas responsáveis pela formação de valores fundamentais e sociabilidade, pelo contrário, esperam que o processo se dê de forma compartilhada. Nessa perspectiva, concordamos com Polônia e Dessen (2005) quando argumentam que, mesmo quando a instituição escolar planeja e implementa um bom programa curricular, a aprendizagem do aluno só é evidenciada quando é cercado de atenção da família e da comunidade. Dessa maneira, para que isso proceda, as escolas devem trabalhar em parceria com as famílias que devem ser orientadas sobre as abordagens e metodologias de ensino para que possam compreender, acompanhar e colaborar com o processo de ensino-aprendizagem. 
Nesse sentido, encontramos a discussão sobre a configuração do processo de ensino-aprendizagem no qual a responsabilidade de professores, tanto generalistas como especialistas, é transferida para os pais, ou seja, os pais precisam assumir um papel de ensinar que não é diretamente seu. Isso também nos alerta para a organização gestão escolar, o que envolve tempo de planejamento, formação continuada, trabalho colaborativo, concepções de professores sobre a especificidade de estudantes da educação especial, entre outros.

$\bigcirc$ que a gente tem que fazer é isso aí, cobrar e cobrar e fazer a nossa parte. Ele faz dever de casa quando mandam, porque também quando não mandam, eu cobro. Eu tenho um caderno de caligrafia que eu por minha conta própria comprei e passo as letrinhas [...] (LUTA, 2018).

Em contrapartida, quando algumas dessas situações são observadas, abrem-se possibilidades de avanços no processo de ensino-aprendizagem, pois a escola não deve mais desconsiderar a necessidade de construir uma aproximação de vínculo com a família, que esclareça, informe e colabore com o trabalho desenvolvido.

Hoje, o meu filho tem uma professora maravilhosa e ele sabe fazer o nome dele e já reconhece letras e números. Meu filho está sendo alfabetizado porque ele tem uma professora boa, então, se eles não têm uma professora boa, nós temos que fazer a nossa parte (RESILIÊNCIA, 2018).

Concordamos com Polonia e Dessen (2005) quando argumentam que a escola deve reconhecer a importância da colaboração dos pais na história e no projeto escolar dos alunos e auxiliar as famílias a exercerem o seu papel na educação, na evolução e no sucesso profissional dos filhos e, concomitantemente, na transformação da sociedade. Dessa maneira, corroboramos que tanto a família como a escola contribuem com a transmissão do conhecimento culturalmente construído e organizado, que emergem como instituições fundamentais, ao passo que contribuem para o desenvolvimento sociocultural numa troca interrelacional. 
Se nós queremos exigir dos profissionais e dos professores que eles cuidem bem dos nossos filhos, nós também temos que dar condições aos professores de trabalhar (LUTA, 2018)

$[\ldots]$

É claro que o professor regente tem um monte de alunos para dar aula e para dar atenção, mas, quando falam que o nosso filho tem que ter acompanhamento e que não tem apoio suficiente, está esperando de quem? Da criança se comportar ali? (COMBATE, 20181 .

No debate realizado, também surgiu a preocupação dos familiares com as condições de trabalho dos professores, o que pode ser estendido para os outros profissionais da escola. Entendemos que as famílias, nessas palavras, reconhecem a precarização do trabalho docente em andamento no Brasil há alguns anos. Em outros momentos, a família entende as condições de trabalho do professor e ao mesmo tempo precisa compreender o andamento do dia a dia escolar.

\section{O que vem a ser o direito de aprender?}

Nos reportamos à Teoria Crítica dos Direitos Humanos de Joaquin Herrera Flores evidenciando, de acordo com o autor, que direito é o

[...] rol que podem julgar as garantias jurídicas na hora de regular as ações e as conquistas dos indivíduos, movimentos e grupos sociais em seus respectivos processos de lutas em busca da obtenção de maior grau de dignidade (FLORES, 201 1, p. 15, tradução nossa).

Enfatizamos que a Constituição Federal de 1988, no artigo 208, preconiza o atendimento educacional especializado às pessoas que à época eram chamadas de portadoras de deficiência. A Lei de Diretrizes e Bases da Educação Nacional n 9.394/96 é mais incisiva ao estipular um capítulo específico para a educação especial. Entendida como modalidade de educação escolar, deve ser oferecida preferencialmente nas redes comuns de ensino que para isso devem assegurar, entre outras questões, no artigo 59: "I...] currículos, métodos, técnicas, recursos educativos e organização específicos, para atender as suas necessidades" (BRASIL, 1996). 
Nesse cenário, a escolarização dos estudantes da educação especial é um direito e dever do Estado. Tal direito está sustentado pelo princípio de que o saber é sistemático, é mais do que uma importante herança social, pois todos nós fazemos e exercemos parte nesse legado como sujeitos histórico-culturais, como nos lembra Cury (2002).

Ademais, de acordo com Lemons (2015), o direito de aprender e do desenvolvimento encontra-se inserido no direito à educação. A autora pondera que a garantia jurídica do direito à educação não assegurou completamente o direito à aprendizagem. No caso dos alunos da educação especial, tanto um quanto o outro têm sido limitados pelas políticas públicas e por práticas docentes desenvolvidas pelos sistemas de ensino e pela escola.

Assim, adentramos no segundo eixo de discussão, que se configura por meio da pergunta "o que vem a ser o direito de aprender?". Aqui, discutiremos a busca dos familiares pela garantia da aprendizagem dos filhos com vista ao direito de aprender.

Eu tive que literalmente brigar, brigar mesmo, discutir e bater boca. É uma coisa muito feia e tenho certeza de que vocês mães e pais que estão aqui, infelizmente, já tiveram que usar desse artifício algumas vezes, e que é muito cansativo a gente ter que brigar por uma coisa que é direito do nosso filho de aprender, não é? [...] Eu tive que brigar com a coordenadora, com a pedagoga, brigar e fazer reuniões, porque o meu filho levava os cadernos para casa sem nada escrito, só garranchos e várias folhas com garranchos (ESPERANÇA, 2018).

[...]

A maioria dos professores olham para mim com cara feia, e é isso que acontece. Tem professora que, quando eu passo na calçada e na hora que me vê, atravessa. Eu não entendo isso, porque é direito de aprender, e nós temos pelo dever de ensinar? Talvez, é o que esteja faltando né? (LUTA, 2018).

Como podemos verificar nos excertos acima, para que o direito de aprender se concretize, há a necessidade, por parte dos familiares, de muita luta, que, podemos dizer, tem por base a reclamação e a briga com gestores e professores, ao passo que o direito de aprender não é uma simples dádiva do Estado. No geral, os direitos garantidos em lei são expressões das demandas formuladas pela sociedade civil em um determinado período histórico, 
construídos e resultantes das lutas e conquistas. Por exemplo, como a luta dos trabalhadores pela redução da jornada de trabalho e pelo direito ao voto universal.

Nessas lutas, insere-se a educação como direito social (art. $6^{\circ}$ ) no rol dos direitos políticos e civis. Isso significa, segundo Cury (2012, p. 149), "[...] o reconhecimento de que ela faz parte das dimensões estruturais da própria consistência do ser humano e fator indispensável da vida social". Mas esse direito social, dentre outros, expresso no ordenamento jurídico, só terá aplicabilidade com a efetivação das políticas públicas. E, como qualquer outra política pública, as políticas da área educacional implicam escolhas e decisões que envolvem indivíduos, grupos e instituições e, portanto, constroem-se na correlação de forças sociais, com identidades políticas e econômicas heterogêneas que se articulam para defender seus interesses.

Nesse mesmo cenário, configurado pelo direito de aprender, é importante pontuar que o laudo médico aparece como um coadjuvante para o "direito à aprendizagem". Em nossa visão, por mais perverso que seja, o laudo traduz o dever do professor de ensinar quando um familiar diz: "Ela tem um laudo que respalda ela". Portanto, há a necessidade de seguir a pista de Flores 16 (2011) e Carballido (2014) quando argumentam que a luta pelos direitos humanos é também a luta pelas garantias de seu cumprimento.

Um aspecto que chama atenção nas falas dos familiares é a sinalização dos pais em relação ao que significa aprender e não aprender.

Meu filho não aprende a escrever e nem a ler e ele também não tem dever de casa. Eles me pediram oito cadernos e eu não mando, porque eles não usam [...] (ENFRENTAMENTO, 20 18 ).

[...]

Pedi para reter o meu filho porque quem não aprende, não pode continuar passando de ano. Eles dizem que não podem reter, mas gente, tem que reter e eu não me importo (BATALHA, 2018).

[...]

As provas que ele fez até o ano passado, ele não fazia nada, só garrancho e tirava 10 e tirava parabéns. Então, ele estava sendo incentivado a não fazer nada, a não ser ninguém e essa foi a minha briga (ESPERA, 2018).

$[\ldots]$ 
No ano passado, a professora não se esforçou, não incentivou ele a aprender e ele estudou o ano todo e foi para casa também sem ler e sem escrever (ESPERANÇA, 2018)

Célio Sobrinho (2009) argumenta que os pais de alunos da educação especial têm expectativas na escolarização de seus filhos e esperam que a escola cumpra a sua função social que, para eles, é importante do ponto de vista da leitura, da escrita e da profissionalização, atingindo um nível mais elevado de ensino.

Em relação à forma de participação dos pais no processo de escolarização dos filhos, Célio Sobrinho (2009) ainda argumenta que os pais esperam que os professores tomem os rumos pedagógicos e façam as melhores escolhas para o trabalho a ser desenvolvido com os estudantes. Inferimos que, mesmo que os pais não tenham um conhecimento pedagógico propriamente dito, eles têm um entendimento do processo educacional e podem, sim, ser parceiros da escola.

[...] quando tem um plantão pedagógico ou quando você vai pegar o boletim da criança, está lá a nota baixa nessas matérias, mas não foi atividade para casa e quando vai na escola questionar: "gente, não tá indo nada, o que que eu posso fazer com ele?" [...] a nota baixa é incompetência da mãe ou da família? [...]. Conversei com o pedagogo esses dias e pedi uma reunião com os professores regentes para ver o que que a gente pode fazer porque eu sei que o meu filho tem capacidade de aprender (FORÇA, 2018).

$[\ldots]$

Se as escolas tivessem um projeto de maximizar as habilidades dos meninos e pegasse essa habilidade do meu filho de comunicação, ia facilitar muito a aprendizagem (OTIMISMO, 2018).

Célio Sobrinho (2009) ainda argumenta que, quando a família participa efetivamente na escola e opina sobre o trabalho pedagógico, é vista como inconveniente, pois entrariam em uma área que não dominam. Nessa direção, concordamos com Dessen (2007) quando afirma que os laços afetivos, estruturados e consolidados, tanto na escola como na família, permitem que os indivíduos lidem com conflitos, aproximações e situações oriundas desses vínculos, aprendendo a resolver os problemas de maneira conjunta ou separada. 
Para finalizar a reflexão, que não se esgota aqui, pontuamos que os relacionamentos interpessoais na escola são importantes, uma vez que nos constituímos como seres humanos nas relações sociais, como podemos ver nos excertos abaixo:

Precisamos que os profissionais nos orientem como lidar com nossos filhos, porque muitas vezes os nossos filhos são rejeitados e são hostilizados (VIDA, 2018).

$[\ldots]$

Meu filho foi agredido e não falava. Ele chegava em casa com marca de beliscão e eu nunca pude ir lá na escola reclamar, porque se eu chegasse lá, o que eu ia ouvir dos professores e das pessoas é que não tinham visto. Então quem vai provar que ele foi agredido? (ENFRENTAMENTO, 2018).

[...]

Sensibilizar, humanizar e entender que são crianças iguais. No início do ano, eu dei uma escapulida no primeiro dia de aula e consegui subir pra sala e falei: 'hoje eu falo'. Aí, cheguei lá e conversei. Pedi licença ao professor e conversei com toda a turma uns quinze minutos e expliquei que meu filho é autista (ESPERANÇ, 2018).

\section{Considerações finais}

Ao longo do texto, foi realizada uma discussão sobre o direito de aprender dos estudantes da educação especial na escola comum, no que diz respeito ao direito à educação, entendendo que o direito de aprender está contido no direito à educação, um princípio da educabilidade de todos.

Foi possível vislumbrar que a luta das famílias dos alunos da educação especial pelo direito de aprender é um possível movimento de mudanças acerca da efetivação da inclusão escolar nas redes de ensino, pois, ao saírem do anonimato, conforme analisa Oliveira (2007, p. 39), "[...] de invisíveis passaram a ser visíveis, de não-problema passaram a ser problema, evidenciando não a inclusão, mas a passagem, a transição qualitativa, de um estado de negação a um estado de problematização". Trata-se de um movimento de resistência em busca de uma nova hegemonia sobre o processo de inclusão escolar que olhe a educação para os direitos humanos. 
Dessa maneira, a educação especial, numa perspectiva de educação inclusiva, como uma proposta pedagógica e campo de conhecimento, deve ser a base para a luta pelo direito de aprendizagem, sem perder de vista as condições de trabalho do professor, da organização dos recursos e das práticas na escola, da acessibilidade, e da relação com a família. Diante disso, delimitar os discursos, ações e práticas é um desafio para atingir um objetivo comum: o direito de aprender dos estudantes da educação especial.

\section{Referências}

BATALHA. Grupo focal. Vila Velha (Espírito Santo), 19 set. 2018.

BATISTA, Karla da Silva Costa. Direitos sociais. In: CASTRO, Carmem Lúcia Freitas de; GONTIJO, Cynthia Rúbia Braga; AMABILE, Antônio Eduardo de Noronha (org.). Dicionário de políticas públicas. Barbacena: Editora da Universidade do Estado de Minas Gerais, 2012.

BRASIL. [Constituição (1988)]. Constituição da República Federativa do Brasil. Brasília: Senado Federal, 1988.

BRASIL. Lei no 9.394 de 20 de dezembro de 1996. Estabelece as Diretrizes e Bases da Educação Nacional. Diário Oficial da União, Brasília, DF, 23 dez. 1996. Seção 1, p. 27833.

BRASIL. Lei n. 13.146, de 6 de julho de 2015. Institui a Lei Brasileira de Inclusão da Pessoa com Deficiência (Estatuto da Pessoa com Deficiência). Diário Oficial União, Brasília, DF, 7 jul. 2015. Seção 1, p. 2.

CARBALLIDO, Manuel Eugênio Gándara. Repensando os direitos humanos a partir das lutas.

Revista Culturas Jurídicas, Campinas, v. 1, n. 2, 2014.

CÉlIO SOBRINHO, Reginaldo. A relação família e escola a partir da processualidade de um fórum de famílias de alunos com deficiência: contribuições de Norbert Elias. 2009. 203 f. Tese (Doutorado em Educação) - Programa de Pós-Graduação em Educação, Universidade Federal do Espírito Santo, Vitória, 2009.

COMBATE. Grupo focal. Vila Velha (Espírito Santo), 19 set. 2018.

CURY, Carlos Roberto Jamil. Direito à educação: direito à igualdade, direito à diferença.

Cadernos de Pesquisa, São Paulo, n. 1 16, p. 245-262, 2002.

CURY, Carlos Roberto Jamil. A educação básica como direito. Cadernos de Pesquisa, São Paulo, v. 38, n. 134, p. 293-303, maio/ago. 2008. 
CURY, Carlos Roberto Jamil. Educação como direito social. In: CASTRO, Carmem Lúcia Freitas de; GONTIJO, Cynthia Rúbia Braga; AMABILE, Antônio Eduardo de Noronha (org.). Dicionário de políticas públicas. Barbacena: Editora da Universidade do Estado de Minas Gerais, 2012.

DESSEN, Maria Auxiliadora Dessen; POLONIA, Ana da Costa. A família e a escola como contextos de desenvolvimento humano. Paidéia, São Paulo, v. 17, n. 36, p. 21-32, jan./ abr. 2007

DUARTE, Clarice Seixas. A educação como um direito fundamental de natureza social. Educação \& Sociedade, Campinas, v. 28, n. 100, p. 691-713, out. 2007.

ENFRENTAMENTO. Grupo focal. Vila Velha (Espírito Santo), 19 set. 2018.

ESPERA. Grupo focal. Vila Velha (Espírito Santo), 19 set. 2018.

ESPERANÇA. Grupo focal. Vila Velha (Espírito Santo), 19 set. 2018.

FARIA FILHO, Luciano Mendes de. Para entender a relação escola-família: uma contribuição da história da educação. Revista em Perspectiva, São Paulo, v. 14, n. 2, p. 44-50, abr./ jun. 2000.

FLORES, Joaquín Henrique. 16 premisas de uma teoria crítica del derecho. In: PRONER, Carol; CORREAS, Oscar (org.). Teoria crítica dos direitos humanos: in memoriam de Joaquín

20 Herrera Flores. Belo Horizonte: Fórum, 2011.

FLORES, Joaquín Henrique. A proposito de la fundamentacion de los derechos humanos y de la interpretación de los derechos fundamentales. Revista de Estudios Políticos, Madri, n. 45, p. 177-212, mayo-lunio, 1985.

FLORES, Joaquín Henrique. La reinvención de los derechos humanos. Andaluzia: Editora Atrapasueños, 2008.

FLORES, Joaquín Henrique. Los derechos humanos en el contexto de la globalización: tres precisiones conceptuales. In: RÚBIO, David Sánches; FLORES, Joaquín Henrique; CARVALHO, Salo de (org.). Direitos humanos e globalização fundamentos e possibilidades desde a teoria crítica. 2. ed. Porto Alegre: EDIPUCRS, 2010.

FORÇA. Grupo focal. Vila Velha (Espírito Santo), 19 set. 2018.

FREITAS, Luiz Carlos de. Os reformadores empresariais da educação e a disputa pelo controle do processo pedagógico na escola. Educação \& Sociedade, Campinas, v. 35, n. 129, p. $1085-1114,2014$.

GOMES, Alberto Albuquerque. Apontamentos sobre a pesquisa em educação: usos e possibilidade do grupo focal. ECCOS Revista Científica, São Paulo, v. 1, n. 1, 2005. 
HELL, lara Belink. Caminhos indiretos no ensino de Biologia celular para alunos com deficiência visual e múltipla. 2020. Dissertação (Dissertação de Mestrado) - Programa de Pós-Graduação em Ensino na Educação Básica, Universidade Federal do Espírito Santo, Vitória, 2020.

HERRERA, Carlos Miguel. Filosofía de los derechos humanos en tiempos de globalización. In: PRONER, Carol; CORREAS, Oscar (org.). Teoria crítica dos direitos humanos: in memoriam de Joaquín Herrera Flores. Belo Horizonte: Fórum, 2011.

LEMONS, Caroline Caldas. Do direito à educação ao direito à aprendizagem: um estudo sobre culturas de intervenção pedagógica. 2015. 197 f. Dissertação (Mestrado em Educação) - Programa de Pós-Graduação em Educação, Universidade de Caxias do Sul, Caxias do Sul, 2015.

LIMA, Antônio Bosco de. Estado, democracia e educação. In: FIGUEIREDO, Irene Marilene Zago; ZANARDINI, Isaura Mônica Souza; DEITOS, Roberto Antônio (org.) Educação, políticas sociais e Estado no Brasil. Cascavel, 2008.

LUTA. Grupo focal. Vila Velha (Espírito Santo), 19 set. 2018.

MAFEZONI, Andressa Caetano; PLETSCH, Márcia Denise. Os conceitos de inteligência e de deficiência intelectual: as mesmas origens? Revista Contrapontos, Itajaí, v. 19, n. 1, p. 392-407, jan./jun. 2019.

MAFEZONI, Andressa Caetano; SIMON, Caroline. A pessoa com deficiência intelectual e as concepções de professores de educação especial. Revista Educação em perspectiva, Viçosa, v. 11, n. 2, p. 1-14, jun./ago. 2020.

MELO, Douglas Christian Ferrari de; MAFEZONI, Andressa Caetano. $\bigcirc$ direito de aprender e os alunos público-alvo da educação especial. Revista Educação em Debate, Fortaleza, v. 41, n. 78, p. 101-115, jan./abr. 2019.

OHIWEILER, Leonel. Políticas públicas. In: BARRETTO, Vicente de Paulo. Dicionário de filosofia política. São Leopoldo: Editora Unisinos, 2010.

OLIVEIRA, Cynthia Bisinoto Evangelista de; MARINHO-ARAÚJO, Claisy Maria. A relação família-escola: intersecções e desafios. Revista Estudos de Psicologia, Campinas, v. 27 , n. 1, p. 99-108, 2010.

OLIVEIRA, Ivanilde Apoluceno. Política de educação inclusiva nas escolas: trajetória de conflitos. In: JESUS, Denise Meyrelles de; BAPTISTA Cláudio Roberto; BARRETO, Maria Aparecida Santos Côrrea; VICTOR, Sônia Lopes. Inclusão, práticas pedagógicas e trajetórias de pesquisa. Porto Alegre: Mediação, 2007.

OTIMISMO. Grupo focal. Vila Velha (Espírito Santo), 19 set. 2018. 
POLONIA, Ana da Costa; DESSEN, Maria Auxiliadora. Em busca de uma compreensão das relações entre família e escola. Revista Psicologia Escolar Educacional, Campinas, v. 9, n. 2, p. 303-312, 2005.

RESILIÊNCIA. Grupo focal. Vila Velha (Espírito Santo), 19 set. 2018.

RESISTÊNCIA. Grupo focal. Vila Velha (Espírito Santo), 19 set. 2018.

SILVA, Plácido de. Vocabulário jurídico conciso. 2. ed. Rio de Janeiro: Forense, 2010.

SIMÕES, Carlos. Teoria e crítica dos direitos sociais: o Estado social e o Estado democrático de direito. São Paulo: Cortês, 2013.

SUPERAÇÃO. Grupo focal. Vila Velha (Espírito Santo), 19 set. 2018.

VIDA. Grupo focal. Vila Velha (Espírito Santo), 19 set. 2018.

VIGOR. Grupo focal. Vila Velha (Espírito Santo), 19 set. 2018.

Prof. Dr. Douglas Christian Ferrari de Melo Universidade Federal do Espírito Santo (Brasil) Programa de Pós-Graduação do Mestrado Profissional em Educação Programa de Pós-Graduação em Educação Departamento de Política e Sociedade Grupo de Estudo e Pesquisa em Fundamentos da Educação Grupo de Estudo e Pesquisa em Cão Guia e Deficiência Visual Orcid id: http:/ / orcid.org/0000-0003-2761-0477 E-mail: dochris.ferrari@gmail.com 
Prof. ${ }^{a} \mathrm{Dr}^{a}$. Andressa Caetano Mafezoni Universidade Federal do Espírito Santo (Brasil) Programa de Pós-Graduação do Mestrado Profissional em Educação Departamento de Teorias do Ensino e Práticas Educacionais Grupo de Pesquisa Formação, Pesquisa-Ação e Gestão de Educação Especial Grupo de Estudos e Pesquisas, Inclusão Escolar e Processos de Ensino-aprendizagem Orcid id: http:/ / orcid.org/0000-0003-0944-2596 E-mail: andressamafezoni@yahoo.com.br

Recebido 18 fev. 2021 Aceito 7 maio 2021 